\title{
Campuran Pemasaran: Satu Kajian Kes di Sebuah Sekolah Rendah Agama di Selangor
}

\author{
Marketing Mix: A Case Study at a Religious Primary School in Selangor \\ Suriani Abdul Hamid ${ }^{\mathrm{a}}$, Khalip Musa ${ }^{\mathrm{b}}$ \\ ${ }^{a}$ Universiti Pendidikan Sultan Idris, Malaysia, suriani@fpe.upsi.edu.my \\ ${ }^{b}$ Universiti Pendidikan Sultan Idris, Malaysia, khalip@fpe.upsi.edu.my
}

\begin{abstract}
Abstrak
Kajian ini bertujuan untuk mengkaji elemen campuran pemasaran yang diamalkan di sebuah sekolah agama di negeri Selangor. Pendekatan kualitatif menggunakan kajian kes digunakan, di mana isu pemasaran sekolah diterokai melalui perbincangan kumpulan fokus dan analisa kandungan. Perbincangan kumpulan fokus melibatkan lapan orang guru yang mengajar di sekolah ini. Hasil kajian menunjukkan kesemua elemen 7P dalam campuran pemasaran (produk, tempat, harga, promosi, manusia, proses dan bukti fizikal) diberikan perhatian yang sewajarnya. Dapatan kajian ini dapat membantu pemimpin sekolah memahami elemen-elemen campuran pemasaran yang penting kepada ibu bapa ketika memilih sekolah untuk anak-anak mereka. Memahami konsep pemasaran ini adalah penting kepada pemimpin sekolah untuk menjadikan sesebuah sekolah terus berdayasaing dalam persekitaran yang kompetitif pada hari ini.
\end{abstract}

Kata kunci: campuran pemasaran, produk, tempat, harga, promosi, proses, bukti fizikal

\begin{abstract}
This study aims to examine the marketing mix elements practiced at a religious school in Selangor. A qualitative approach using case studies are employed, where school marketing issues are explored through focus group discussion and content analysis. The focus group discussion involves eight teachers who teach at this school. The results show that all the 7 elements (7Ps) in marketing mix (product, place, price, promotion, people, process and physical evidence) are given due attention. The findings of this study can assist school leaders to understand the marketing mix elements that are important to parents when choosing a school for their children. Understanding the concept of marketing is vital to school leaders to remain competitive in today's competitive environment.
\end{abstract}

Keywords: marketing mix, product, place, price, promotion, process, physical evidence

\section{PENGENALAN}

Pendidikan merupakan keperluan asas yang mesti dimiliki oleh setiap individu dalam masyarakat pada hari ini. Namun, keperluan pendidikan bagi setiap individu adalah berbeza. Oleh itu, sekiranya pihak sekolah ingin memenuhi keperluan dan keinginan ibu bapa dan pelajar, dan dalam skop yang lebih luas kerajaan, industri dan masyarakat, kepimpinan yang berkesan adalah penting (Bush, 2011). Kejayaan sesebuah sekolah sangat bergantung pada kualiti pengurusan dan kepimpinannya. Bush (2011) mengkaji kepimpinan sekolah di negara-negara maju dan membangun, dan berpendapat bahawa sekolah memerlukan pemimpin dan pengurus yang berkesan sekiranya mereka berhasrat untuk menyediakan pendidikan terbaik kepada pelajar 
mereka. Salah satu fungsi pengurusan yang penting dan tidak boleh diabaikan oleh pemimpin sekolah untuk bertahan dalam persekitaran yang bersaing pada hari ini adalah pemasaran. Pemasaran bukan hanya berkisar tentang penjualan, promosi atau pengiklanan. Pemasaran mesti dilihat sebagai satu proses pengurusan yang holistik (Foskett, 2002) dan harus diintegrasi dengan peranan pengurusan dalam organisasi (Bowles, Furse \& Tomlinson,1989). Foskett (2002) seterusnya mencadangkan bahawa pemasaran bukan hanya sekadar memenuhi keperluan organisasi sekolah untuk kelangsungan hidup dan mencapai kejayaan, tetapi memenuhi keperluan dan keinginan masyarakat untuk mendapatkan taraf pendidikan yang tinggi. Oleh itu, pemasaran adalah fungsi pengurusan yang tidak boleh diabaikan oleh pemimpin sekolah yang ingin berkembang atau bertahan dalam persekitaran yang kompetitif pada hari ini (Oplatka \& HemsleyBrown, 2007).

Kajian ini dijalankan bagi memahami amalan pemasaran di sekolah dengan memberi tumpuan terhadap elemen-elemen dalam campuran pemasaran, iaitu produk, tempat, harga, promosi, manusia, proses dan bukti fizikal. Sekolah yang dikaji merupakan sebuah Sekolah Rendah Agama Integrasi di Selangor dan merupakan sekolah dibawah kelolaan Jabatan Agama Islam Selangor (JAIS). Sekolah ini ditubuhkan pada tahun 1994 dan kini mempunyai 1,217 pelajar dan 115 orang kakitangan, dimana 94 daripadanya adalah guru. Sekolah ini menggabungkan kurikulum agama dan Kurikulum Bersepadu Sekolah Rendah (KBSR)

\section{SOROTAN LITERATUR}

Konsep pemasaran sekolah bukanlah sesuatu yang baru. Pemasaran pendidikan telah diperkenalkan ke dalam pendidikan di negara-negara barat sejak tahun 1980-an dan 1990-an (Oplatka, Hemsley-Brown \& Foskett, 2002). Kajian-kajian mengenai pemasaran sekolah antara lain memberi fokus terhadap persepsi pemasaran sekolah (Grace, 1995; James \& Philips, 1995; Oplatka et al, 2002), etika dalam pemasaran sekolah (Harvey \& Busher, 1996), tanggungjawab pemasaran di sekolah (James \& Philips, 1995, Oplatka, 2007), kesan pemasaran kepada pemimpin sekolah (Oplatka et al, 2002) dan orientasi pasaran dalam budaya sekolah (Drysdale, 1999; Oplatka \& Hemsley-Brown, 2007). Namun, disiplin pemasaran sekolah tidak diperkenalkan secara meluas dan dikaji dalam konteks Malaysia.

Di Malaysia, kajian dalam pemilihan dan pemasaran sekolah adalah sangat terhad. Keadaan ini berlaku berkemungkinan disebabkan pelajar ditempatkan di sekolah berdasarkan alamat kediaman. Walau bagaimanapun, selepas peperiksaan UPSR yang diduduki semasa Darjah 6 di sekolah rendah, pelajar dibenarkan memilih sekolah menengah berdasarkan keputusan UPSR atau minat mereka. Pihak yang berkaitan seperti Kementerian Pendidikan atau Jabatan Agama Negeri akan menentukan dan menempatkan pelajar ke sekolah berkenaan dengan mengambil kira pilihan yang telah dibuat oleh pelajar.

Antara artikel yang diterbitkan mengenai pemilihan sekolah termasuklah pemilihan ibubapa terhadap prasekolah (Dahari \& Ya, 2006) dan pemilihan ibu bapa Melayu di Sekolah Rendah Cina (Sua, Ngah \& Md Darit, 2013). Dahari dan Ya (2006) mendapati ibu bapa memilih pra- 
sekolah tertentu kerana jenama, sekolah dikendalikan oleh pihak swasta, keselamatan, kualiti pengajaran dan kebersihan. Kajian mereka juga mendapati, sekolah yang menggunakan medium bahasa Inggeris dan sekolah berasaskan agama menjadi pilihan ibu bapa. Sua, Ngah dan Md Darit (2013) mendapati harapan ibu bapa terhadap pembelajaran anak dalam pencapaian akademik merupakan faktor utama yang mempengaruhi kemasukan pelajar Melayu di sekolah rendah Cina. Faktor lain termasuk kualiti pengajaran, nilai instrumental bahasa Cina, memperkukuh hubungan etnik dan mempelajari bahasa dan budaya Cina. Mukhriz et al. (2011) menegaskan bahawa pemilihan dan persaingan wujud dalam sistem sekolah di Malaysia. Ini dibuktikan oleh jenis sekolah yang berbeza bagi memenuhi keperluan yang berbeza. Kajian tersebut turut mendapati ramai ibu bapa menyatakan bahasa, perbezaan etnik dikalangan pelajar, dan pelajaran agama, sebagai motivasi utama untuk memilih sesebuah sekolah.

Selain itu terdapat juga kajian-kajian mengenai pemasaran sekolah di Malaysia yang dijalankan oleh pelajar pasca siswazah untuk tesis mereka. Marcea (2006) mendapati faktor-faktor yang mempengaruhi ibu bapa untuk menghantar anak-anak ke sekolah antarabangsa adalah reputasi sekolah kerana mempunyai akademik yang baik, keinginan untuk anak-anak belajar dalam bahasa Inggeris, saiz kelas yang kecil dan kelayakan yang diiktiraf di peringkat antarabangsa. Ibu bapa dalam kajian Kiong (1998) menyatakan mereka memilih sekolah Islam swasta kerana sekolah ini memberi tumpuan kepada ajaran Islam, peraturan yang ketat dan guru yang rajin. Hasil akademik, dan faktor masyarakat memainkan peranan penting dalam mempengaruhi kepuasan ibu bapa dalam kajian Hui (2008). Hui (2008) juga melaporkan bahawa ibu bapa berpuas hati dengan saiz kelas kecil, nisbah guru/pelajar yang kecil, gaya mengajar, komunikasi dalam bahasa Inggeris dan gabungan pelbagai kaum yang terdapat di sekolah. Ketiga-tiga kajian ini dijalankan di sekolah swasta, menunjukkan kekurangan penyelidikan di sekolah awam di Malaysia.

Dalam membina imej sekolah dan meningkatkan kesetiaan ibu bapa, strategi pemasaran yang berkesan adalah penting (Li \& Hung, 2007). Campuran pemasaran yang merangkumi produk, tempat, harga, promosi, proses, bukti fizikal dan manusia (Evans, 1995; Foskett, 1998; Gray, 1991; Harvey \& Busher, 1996, James \& Philips, 1995) perlu dilaksanakan dengan berkesan.

Produk adalah sesuatu yang ditawarkan kepada pasaran dan mampu memuaskan keperluan dan kehendak pelanggan. Dalam konteks sekolah, unsur terpenting produk yang ditawarkan ialah perkhidmatan mendidik pelajar. Ini termasuk kurikulum sekolah, opsyen kurikulum yang ditawarkan di sekolah, cara penyampaian dan aktiviti kokurikulum (Walters 1993 seperti yang dinyatakan dalam Evans, 1995) persekitaran penyayang, etos dan pencapaian akademik (James \& Philips, 1995). Tempat pula merujuk kepada bagaimana produk tersebut diagihkan (Evans, 1995). Ini termasuk persekitaran fizikal sekolah, bilik darjah, kemudahan, bangunan dan kawasan sekolah, jadual waktu dan saiz kelas (Evans, 1995). Dari segi harga, selain yuran sekolah, harga dapat dilihat dari segi usaha yang diperlukan untuk mendapat akses ke sekolah, seperti kelayakan kemasukan yang harus dipenuhi oleh pelajar (Stott \& Parr, 1991 yang dinyatakan dalam Harvey \& Busher, 1996).

Promosi merujuk kepada sebarang aktiviti untuk menyampaikan manfaat perkhidmatan kepada bakal pelanggan (James \& Philips, 1995). Ini termasuk pengiklanan, promosi jualan, jualan 
peribadi, publisiti dan perhubungan awam. Manusia merujuk kepada semua faktor manusia yang memainkan peranan dalam penyampaian perkhidmatan dan dengan itu mempengaruhi persepsi pelanggan (Harvey \& Busher, 1996). Ini termasuk keupayaan guru, kemahiran, pengetahuan, pengalaman, keperihatinan guru terhadap pelajar, dan pemasaran dalaman (James \& Philips, 1995). Proses merujuk kepada prosedur, mekanisme dan aliran aktiviti di mana perkhidmatan tersebut disampaikan. Seperti yang dinyatakan sebelum ini, sistem pendidikan secara keseluruhannya mempunyai kurikulum yang sama, tetapi guru-guru yang memberi perkhidmatan adalah berbeza. Oleh itu, tanpa proses pengurusan yang baik, kualiti pengajaran dan pembelajaran boleh dipersoalkan (Evans, 1995; Harvey \& Busher, 1996 dan Zeithaml, Bitner \& Gremler, 2013).

Bukti fizikal merujuk kepada persekitaran di mana perkhidmatan tersebut disampaikan dan di mana organisasi dan pelanggan berinteraksi, serta komponen-komponen nyata yang meningkatkan prestasi perkhidmatan yang disampaikan (Zeithaml, Bitner \& Gremler, 2013), seperti kemudahan, peralatan, papan tanda, bahan komunikasi, objek, pekerja, pelanggan lain, dan harga (Shanker, 2002). Dalam konteks sekolah, bukti fizikal melibatkan kualiti dan suasana kelas (Bowles, Furse \& Tomlinson, 1989), kemudahan sukan dan bilik umum (Foskett, 1998).

Ibu bapa tertarik dengan sekolah agama kerana "pembangunan identiti" yang diterapkan oleh sekolah jenis ini dalam mewujudkan masyarakat Islam yang bertamadun (Deviyati, 2016). Butler dan Hamnett (2012) menyatakan bahawa sekolah berasaskan agama adalah pilihan yang popular kepada ibu bapa kerana sekolah jenis ini dianggap boleh mendidik pelajar-pelajar untuk memiliki tingkah laku yang baik.

\section{METODOLOGI KAJIAN}

Kajian yang dijalankan ini berbentuk kajian kes dan menggunakan pendekatan kualitatif. Kaedah perbincangan kumpulan fokus digunakan untuk mendapatkan maklumat yang lebih luas dan pelbagai berkenaan campuran pemasaran yang dilaksankan di sekolah. Seramai lapan orang guru yang mengajar di sekolah kajian kes ini telah dipilih untuk menyertai kumpulan fokus ini. Guruguru ini juga merupakan pelajar yang sedang mengikuti pengajian separuh masa di sebuah universiti di Semenanjung Malaysia.

Perbincangan dijalankan semasa guru-guru ini menghadiri kuliah di universiti berkenaan dan dikendalikan oleh penyelidik sebagai moderator. Soalan separa berstruktur berkenaan setiap elemen dalam campuran pemasaran diajukan dalam perbincangan ini. Setelah moderator menerangkan maksud sesuatu elemen campuran pemasaran, guru-guru ini melontarkan pandangan mereka dan mereka dikehendaki menulis perlaksanaan elemen campuran pemasaran tersebut di atas kertas dengan bimbingan moderator. Kertas ini diserahkan kepada moderator di akhir perbincangan. Kandungan data yang diperolehi ini dianalisis mengikut tema. 


\section{DAPATAN KAJIAN}

Hasil kajian mendapati sekolah yang dikaji telah membangunkan satu program pemasaran bersepadu, sama ada secara eksplisit atau tersirat, yang akan dibincangkan menggunakan tujuh alat campuran pemasaran - produk, tempat, harga, promosi, manusia, proses dan bukti fizikal.

\section{Produk}

Dalam konteks sekolah, produk termasuk kurikulum sekolah, opsyen kurikulum yang ditawarkan di sekolah, cara penyampaian dan aktiviti kokurikulum (Walters 1993 seperti yang dinyatakan dalam Evans, 1995) persekitaran penyayang, etos dan pencapaian akademik (James \& Philips, 1995). Sekolah ini menawarkan gabungan tiga kurikulum iaitu kurikulum Kementerian Pelajaran Malaysia, Kurikulum Jabatan Kemajuan Islam Malaysia dan Kurikulum Jabatan Agama Islam Selangor bertepatan dengan kehendak ibubapa yang mahukan keseimbangan pendidikan agama dan akademik. Di samping itu,sekolah juga menerapkan nilai kerohanian, di mana solat dhuha dijalankan sebanyak empat kali seminggu, solat zuhur dilakukan secara berjemaah, bacaan Yassin pada setiap hari Jumaat minggu terakhir semasa perhimpunan, berpuasa pada hari khamis berserta majlis berbuka puasa khususnya untuk murid tahun enam, serta selawat dan doa sebelum pulang ke rumah.

Dalam bidang sukan, walaupun sekolah ini bukan merupakan sekolah kelolaan Kementerian Pelajaran Malaysia, murid di sekolah ini berpeluang menyertai sukan yang dianjurkan oleh Majlis Sukan Sekolah Sekolah Daerah (MSSD) dan Majlis Sukan Sekolah Sekolah Selangor (MSSS). Pencapaian akademik sekolah ini juga adalah memberangsangkan. Sekolah ini memperolehi keputusan yang cemerlang dalam peperiksaan awam. Sebagai contoh pada tahun 2016, seramai 81 orang murid mendapat 8A dalam peperiksaan Ujian Penilaian Kelas KAFA (UPKK) yang diduduki oleh pelajar tahun lima.

\section{Tempat}

Tempat merujuk kepada bagaimana produk tersebut diagihkan termasuk persekitaran fizikal sekolah, bilik darjah, kemudahan, bangunan dan kawasan sekolah, jadual waktu dan saiz kelas (Evans, 1995). Terdapat enam kelas untuk setiap tahun yang menempatkan antara 35-40 orang murid dalam setiap kelas. Kelas-kelas ini dilengkapi dengan loker bagi setiap murid bagi menyimpan buku dan barang-barang mereka. Susunan meja berdasarkan pembelajaran abad ke21 menepati keperluan pengajaran dan pembelajaran. Kelas yang menempatkan murid darjah satu berada di aras satu bagi menjamin keselamatan murid dan memudahkan mereka untuk naik dan turun tangga. Jadual anjal disediakan dan disusun dengan memasukkan waktu-waktu solat seperti solat dhuha dan solat fardhu. Waktu persekolahan bermula jam 7.40 pagi dan berakhir pada jam 3.30 petang. Manakala pada hari Rabu murid-murid akan mengikuti aktiviti kokurikulum bermula jam 3.30 petang hingga 5.00 petang. Pada hari isnin hingga Khamis satu masa diperuntukkan untuk solat dhuha. 
Terdapat banyak kemudahan disediakan bagi membantu proses pengajaran dan pembelanjaran berjalan lancar. Sekolah ini mempunyai tiga buah surau yang digunakan untuk pelbagai aktiviti serta solat. Kemudahan lain termasuk makmal komputer, makmal sains, bengkel kemahiran hidup, stor sukan, bilik tayangan, dan perpustakaan,

\section{Harga}

Dalam konteks pemasaran sekolah, yuran sekolah bukanlah satu-satunya elemen harga yang harus diberi perhatian, harga juga termasuk usaha yang diperlukan untuk mendapat akses ke sekolah, seperti kelayakan kemasukan yang harus dipenuhi oleh pelajar (Stott \& Parr, 1991 yang dinyatakan dalam Harvey \& Busher, 1996). Kemasukan ke sekolah ini adalah melalui ujian kelayakan darjah satu. Ujian ini meliputi ujian bertulis dan secara lisan. Tawaran hanya akan diberikan kepada murid yang layak sahaja. Kos pengangkutan bukan merupakan masalah kepada murid-murid di sekolah ini, kerana mereka tinggal di kawasan yang berhampiran. Oleh itu kos pengangkutan yang terlibat tidak besar. Selain itu ibubapa yang menghantar anak ke sekolah ini juga dapat menjimatkan kos dan masa kerana anak mereka hanya bersekolah di satu sekolah sahaja. Mereka tidak perlu berkejar masa dan mengeluarkan kos untuk dua sesi persekolahan yang berbeza di sekolah yang berbeza untuk pendidikan akademik dan agama. Walaupun penjaga perlu membayar yuran makan kepada pihak sekolah, kerana pakej makan tengahari disediakan kepada pelajar, tetapi harga yang dikenakan adalah berpatutan.

\section{Promosi}

Promosi merujuk kepada sebarang aktiviti untuk menyampaikan manfaat perkhidmatan kepada bakal pelanggan. Banyak aktiviti promosi dijalankan oleh pihak sekolah. Pihak sekolah menggunakan kain rentang, laman web sekolah, dan media sosial untuk menyampaikan maklumat kepada penjaga dan masyarakat sekitar. Sebagai contoh bagi kemasukan ke darjah 1, pihak sekolah menggunakan kain rentang dan laman web sekolah untuk memberitahu kepada penjaga yang ingin menghantar anak mereka ke sekolah ini, di mana maklumat terperinci berkenaan tarikh permohonan dibuka, tarikh pendaftaran, tarikh ujian kelayakan dan tarikh tutup permohonan disebarkan melalui medium ini.

Selain itu bagi menarik kehadiran penjaga untuk menyertai aktiviti yang dijalankan oleh pihak sekolah, aktiviti promosi jualan dilakukan, seperti cabutan bertuah dan tawaran berkembar. Sebagai contoh cabutan bertuah dijalankan dipenghujung Mesyuarat PIBG bagi memastikan penjaga tidak pulang awal sebelum mesyuarat tamat. Manakala tawaran berkembar diberikan kepada penjaga yang menghantar anak mereka untuk kelas tambahan yang melebihi daripada satu subjek. Contohnya, bayaran untuk satu subjek kelas tambahan adalah RM10, tetapi penjaga yang menghantar anak mereka untuk empat subjek hanya perlu membayar RM35. Bagi menggalakkan penjaga membuat pembayaran penuh yuran sekolah, diskaun akan diberikan kepada penjaga yang membuat bayaran penuh sebelum bulan Mac.

Manakala semasa hari terbuka, guru bertindak sebagai agen pemasaran. Selain berbincang tentang pencapaian akademik pelajar, guru juga menyampaikan maklumat-maklumat lain berkaitan 
sekolah. Bagi memberitahu pihak awam tentang program-program dan aktiviti yang telah dijalankan, pihak sekolah menerbitkan majalah sekolah. Sekolah juga mempunyai hubungan yang baik dengan pihak akhbar di mana berita tentang pencapaian cemerlang sekolah ini sering diterbitkan di akhbar.

\section{Manusia}

Faktor manusia termasuk keupayaan guru, kemahiran, pengetahuan, pengalaman, keperihatinan guru terhadap pelajar, dan pemasaran dalaman (James \& Philips, 1995). Majoriti guru di sekolah ini mempunyai lebih daripada 10 tahun pengalaman dalam bidang pendidikan. Guru-guru di sekolah ini mempunyai kelayakan yang pelbagai berdasarkan bidang mereka. Mereka juga mengikuti kursus dalam perkhidmatan secara berkala bagi meningkatkan kemahiran, dan ramai dalam kalangan guru di sekolah ini yang tidak mempunyai ijazah kini menyambung pengajian di peringkat ijazah sarjana muda. Selain guru, terdapat empat orang kakitangan sokongan yang membantu urusan pentadbiran di sekolah ini.

Guru-guru di sekolah ini menunjukkan keperihatinan yang tinggi terhadap murid. Sebagai contoh, guru akan membantu murid yang terlupa membawa duit, hilang duit atau tidak cukup duit pada waktu rehat melalui unit kebajikan sekolah. Perkhidmatan meminjamkan baju dan seluar untuk menggantikan pakaian yang kotor seperti murid mempunyai masalah cirit-birit atau muntah juga disediakan. Unit kebajikan sekolah juga akan memberikan sumbangan kewangan dan peralatan sekolah kepada murid-murid yang kurang berkemampuan.

\section{Proses}

Proses merujuk kepada prosedur, mekanisme dan aliran aktiviti bagi memastikan penyampaian perkhidmatan yang lancar. Ini termasuklah proses pengurusan, pendaftaran, dan pengajaran dan pembelajaran. Berdasarkan analisis kandungan catatan guru yang terlibat dalam kajian ini, didapati elemen proses diberi perhatian oleh pihak sekolah. Contohnya, proses kemasukan ke darjah satu adalah sangat teratur, bermula dari penjaga membeli borang pendaftaran dan borang ujian kelayakan sehingga murid yang berjaya menghadiri orientasi sebelum bermula sesi persekolahan. Begitu juga dari segi proses pengajaran dan pembelajaran, di mana bilangan murid untuk kelas di hadapan (pelajar yang cemerlang) adalah lebih ramai berbanding di kelas hujung (pelajar lemah). Ini dilakukan bagi memastikan murid di kelas hujung ini mendapat perhatian dan bimbangan yang lebih personal daripada guru yang mengajar.

\section{Bukti fizikal}

Oleh kerana produk pendidikan adalah tidak ketara, bukti fizikal memainkan peranan penting sebagai bukti perkhidmatan yang akan disampaikan. Ini termasuklah kemudahan, peralatan, papan tanda, bahan komunikasi, objek, pekerja, pelanggan lain dan lain-lain bukti ketara yang mencerminkan kualiti perkidmatan yang disampaikan. Semua bukti fizikal ini akan menyumbang kepada persepsi penjaga terhadap kualiti sesebuah sekolah. Berdasarkan analisis kandungan catatan guru yang terlibat dalam kajian ini, sekolah ini menyediakan persekitaran yang kondusif. 
Empat blok tiga tingkat yang menempatkan pejabat dan bilik darjah diselenggara dengan baik. Bangunan ini juga dicat setiap lima tahun dengan peruntukan daripada pihak JAIS. Kemudahan lain termasuk tiga buah surau, tandas, kantin, makmal komputer, makmal sains, bengkel kemahiran hidup, stor sukan, bilik tayangan, perpustakaan, telefon awam, bilik rawatan, gazebo untuk pelajar beristirehat dan koperasi sekolah.

Terdapat banyak papan tanda tunjuk arah diletakkan di sekolah ini bagi memudahkan murid dan ibu bapa serta pihak luar berurusan dengan pihak sekolah. Selain itu papan tanda yang mengandungi doa dan perkataan yang mudah untuk dibaca dan diingati murid juga diletakkan di kaki lima bangunan sekolah. Nama murid cemerlang yang mengharumkan nama sekolah dipamerkan diatas kain rentang dan digantung di pintu utama sekolah. Tempat letak kereta guru ditempatkan di bahagian belakang sekolah dengan kemudahan pintu pagar dan jauh dari laluan murid bagi mengelakkan kesesakan sewaktu datang dan pulang dari sekolah. Khidmat pengawal keselamatan yang mengawal sekolah selama 24 jam disediakan untuk mengawal urusan keluar masuk sekolah. Setiap pintu masuk sekolah dikunci sepanjang sesi persekolahan dan hanya akan dibuka apabila waktu pulang atau datang ke sekolah.

\section{PERBINCANGAN DAN KESIMPULAN}

Sekolah yang dikaji mengamalkan kesemua elemen campuran pemasaran pada tahap yang memuaskan dan usaha pemasaran jelas dilaksanakan di sekolah ini. Maka tidak hairanlah sekolah ini menjadi pilihan ibu bapa untuk menghantar anak mereka ke sekolah ini. Dapatan kajian ini selari dengan Butler dan Hamnett (2012) yang menyatakan bahawa sekolah berasaskan agama adalah pilihan yang popular di kalangan ibu bapa kerana pelajar-pelajar di sekolah ini dianggap mempunyai tingkah laku yang terpuji. Deviyati (2016) menyatakan pembangunan identiti yang diterapkan oleh sekolah jenis ini dalam mewujudkan masyarakat Islam yang bertamadun. Tingkah laku terpuji dan pembangunan identiti ini adalah hasil daripada amalan-amalan kerohanian yang dijalankan oleh pihak sekolah, seperti yang dinyatakan dalam dapatan kajian ini, di mana solat dhuha dijalankan sebanyak empat kali seminggu, solat zuhur dilakukan secara berjemaah, bacan Yassin pada setiap hari Jumaat minggu terakhir semasa perhimpunan, berpuasa pada hari khamis berserta majlis berbuka puasa khususnya untuk murid tahun enam, serta selawat dan doa sebelum pulang ke rumah.

Selain itu, faktor-faktor berkaitan akademik yang dianggap penting dalam banyak kajian-kajian sebelum ini (Burgess et al, 2009; Jackson \& Brisset, 2005) juga disokong oleh dapatan kajian ini. Gabungan tiga kurikulum iaitu kurikulum Kementerian Pelajaran Malaysia, Kurikulum Jabatan Kemajuan Islam Malaysia dan Kurikulum Jabatan Agama Islam Selangor ditawarkan, dan sekolah ini juga menunjukkan prestasi yang cemerlang dalam peperiksaan awam.

Dalam organisasi perkhidmatan seperti sekolah, ibu bapa menggunakan petunjuk ketara untuk menilai kualiti perkhidmatan. (Shanker, 2002). Keadaan ini dapat dilihat di sekolah ini, dimana sekolah ini menyediakan persekitaran yang kondusif dan kemudahan yang baik bagi mencerminkan kualiti perkhidmatan yang disampaikan. Di samping itu, proses-proses 
pengurusan, pendaftaran, dan pengajaran dan pembelajaran juga didapati teratur. Pengurusan proses yang baik seperti ini adalah penting, dan sekiranya tidak diuruskan dengan baik kualiti pengajaran dan pembelajaran boleh dipersoalkan (Evans, 1995; Harvey \& Busher, 1996 dan Zeithaml, Bitner \& Gremler, 2013).

Bagi menyediakan pendidikan berkualiti tinggi yang dapat meningkatkan imej sekolah, pemimpin sekolah harus memahami elemen pemasaran yang dipertimbangkan oleh ibu bapa dan masyarakat ketika membuat keputusan memilih sekolah. Memahami faktor-faktor yang mempengaruhi keputusan mereka dapat membantu pihak sekolah untuk memberi tumpuan terhadap strategi pemasaran yang sesuai dan memberi fokus kepada elemen campuran pemasaran yang betul. Ini penting kerana setiap elemen dalam 7P yang dinyatakan (produk, tempat, harga, promosi, manusia, proses dan bukti fizikal) adalah saling berkaitan dan merupakan elemen-elemen yang boleh dikawal bagi membentuk sekolah untuk menjadi lebih berdaya saing.

Kajian seumpama ini boleh dikembangkan lagi di masa hadapan ke atas sampel yang lebih besar meliputi sekolah agama lain bukan sahaja di Selangor malah di negeri-negeri lain. Hal ini bagi mendapatkan gambaran yang lebih jelas dan menyeluruh tentang pemasaran sekolah dan dapatan kajian dapat digeralisasikan.

\section{RUJUKAN}

Bowles, G, Furse, J., \& Tomlinson, H. (1989). Marketing and promotions: aspects of marketing in schools. In Fidler, B., \& Bowles, G, (Eds). Effective Local Management of Schools (pp. 36-57), Longman, Harlow.

Burgess,S., Greaves, E., Vignoles, A., \& Wilson, D. (2009). What parents want: school preferences and school choice, Working Paper No. 09/222 Centre for Market and Public Organisation, Bristol Institute of Public Affairs, University of Bristol

Bush, T. (2011). Theories of educational leadership and mangement. Fourth Edition, SAGE Publication, London

Butler, T \& Hamnet, C. (2012). Praying for success: Faith schools and school choice in East London. Geoforum, 42, pp 1242-53.

Dahari, Z., \& Ya, M.S. (2011). Factors that influence parents' choice of pre-schools education in Malaysia: an exploratory study. International Journal of Business and Social Science, 2 (15), 115-128.

Deviyaty, A. (2016). The potential of independent religious schools: a case study of al-Amin. Brief IDEAS, No 4

Drysdale, L. (1999). Marketing vs market orientation, what's the difference, prime focus. The Professional Journal for Australian Primary School Leaders, April, 28-29.

Evans, I. (1995). Marketing for schools. Cassell: London.

Foskett, N. (1998). Schools and marketization. Educational Management and Administration, 26 (2), 197210.

Foskett, N. (2002). Marketing. In Bush, T. and Bell, L. (Eds) (pp. 241-257). The Principles and Practice of Educational Management. Paul Chapman, London.

Grace, G. (1995). School leadership: beyond education management. Falmer: London.

Gray, L. (1991). Marketing education. Open University Press, Milton Keynes. 
Harvey, J.A., \& Busher, H. (1996). Marketing schools and consumer choice. International Journal of Educational Management, 10 (4), 26-32.

Hui, T. (2008). Parental choice and satisfaction in private school in Karambunai Electoral Zone, Sabah. Unpublished Masters thesis, Universiti Malaysia Sabah, Malaysia.

Jackson \& Bisset. (2005). Gender and school choice: factors influencing parents when choosing single-sex or co-educational independent schools for their children. Cambridge Journal of Education, 35(2), 195211.

James, C., \& Phillips, P. (1995). The practice of educational marketing in schools. Educational Management and Administration, 23 (2), 75-88.

Kiong. (1998). Parental choice of Islamic private secondary school. Unpublished master thesis, Universiti Utara Malaysia, Kedah, Malaysia.

Li, C.K., \& Hung, C.H. (2007). Marketing tactics and parents' loyalty: the mediating role of school image, Journal of Educational Administration, 47(4), 477-489.

Marcea, I. (2006). Spheres of influence: understanding International School choice in Malaysia, Unpublished Master thesis, Queens University, Canada.

Muhriz, T.A., Abdullah, A., and Wan Jan, W.S. (2011). Choice, competition and the role of private providers in the Malaysian school system. The Institute for Democracy and Economic Affairs (IDEAS), CfBT Education Trust.

Oplatka, I., Hemsley-Brown, J., \& Foskett, N.H. (2002). The voice of teachers in marketing their school: personal perspectives in competitive environments. School Leadership and Management, 22 (2), 177196.

Oplatka, I., \& Hemsley-Brown, J. (2007). The incorporation of market orientation in the school culture: An essential aspect of school marketing. International Journal of Educational Management, 21(4), 292305.

Shanker, R. (2002). Services marketing: The Indian perspective. Excell Book, New Delhi.

Sua, T.Y., Ngah, K., \& Darit, S. (2013). Parental choice of schooling, learning process and inter-ethnic friendship patterns: The case of Malay students in Chinese primary schools in Malaysia. International Journal of Educational Development, 33(4), 325-336.

Zeithaml, V.A., Bitner M.J., \& Gremler, D.D. (2013). Services marketing. ${ }^{\text {th }}$ Edition, Mc Graw-Hill. 